Res Publica. Revista de Historia de las Ideas Políticas ISSN: 1576-4184

http://dx.doi.org/10.5209/RPUB.54996

\title{
La eugenesia de la hispanidad de Vallejo Nágera y su introducción en Latinoamérica
}

\author{
Francisco José Robles*, Vicente Caballero**
}

Recibido: 05 de febrero de 2015 / Aceptado: 21 de octubre 2016

\begin{abstract}
Resumen. La Eugenesia de Antonio Vallejo Nágera corre paralela a la idea de Hispanidad, la cual presenta una estructura dual compuesta por la Raza y la Patria que quedan engranadas en el tradicionalismo católico. Se trata de mostrar tal lógica eugenésica a través de la subrepticia contradicción con que el autor acoge a la eugenesia nacionalsocialista o bien de exhibir su influjo en la labor que como psiquiatra desarrolló en los campos de concentración franquistas. Para contextualizar en el tiempo y en el espacio se hace una presentación de la importancia que tuvo la cuestión eugénica en Latinoamérica, con especial énfasis en el caso argentino. Finalmente, se hace una valoración crítica acerca de la discusión en torno a la pertinencia histórica de la dicotomía eugenesia positiva/eugenesia negativa a la que se pone en relación con el problema lamarckismo/darwinismo a principios del siglo XX.
\end{abstract}

Palabras clave: eugenesia; hispanidad; patria; raza; nacional-catolicismo.

\section{[en] Vallejo Nágera's Eugenics of Hispanity and its Introduction in Latin America}

\begin{abstract}
Vallejo Nágera's approach to eugenics runs in parallel with his Hispanity conception. This conception presents a dual structure supported by two concepts: race and motherland. Both are deeply ingrained in catholic traditionalism. The article presents eugenic logic in two ways: on one hand, by showing the surreptitious contradiction behind the particular way in which Vallejo Nágera took up the nazi eugenics and, on the other hand, by tracking its influence on his work at francoist concentration camps. In order to know thoroughly the context, the authors make a review of eugenics subject throughtout Latin America and strongly focus on Argentina. Finally, a critical appraisal on the dichotomy between positive and negative eugenics is linked to the "Lamarckism vs. Darwinism" problem in the early twentieth century.
\end{abstract}

Keywords: eugenics; hispanity; motherland; race; national-catholicism.

\section{Acotación de la eugenesia de la hispanidad}

La obra de Antonio Vallejo Nágera ha sido recobrada en los dos últimos decenios tanto desde el ámbito académico como en prensa - para destacar primordialmente la labor de cobertura científica que el autor prestó a la represión franquista ejercitada en

* Universidad Complutense de Madrid fjrobles@filos.ucm.es

** Universidad Complutense de Madrid vicente.caballero@educa.madrid.org 
particular sobre los presos y presas republicanos, y por extensión sobre los miembros del bando republicano en su conjunto ${ }^{1}$. Es obvio que en modo alguno cabe dudar de la necesidad y relevancia de la investigación realizada sobre este aspecto de la práctica profesional del psiquiatra palentino, pero igualmente es ineludible advertir que esta dimensión de su obra solo cobra figura si se atiende al fondo que le es inherente; el mismo es tematizado en las obras que el autor da a la imprenta en la década de los años treinta del pasado siglo, pero que toma cuerpo cierto más precisamente en los escritos que publica durante la Guerra Civil. En dichos textos están contenidas y esclarecidas las preocupaciones biopolíticas de Vallejo, siendo el grueso de las mismas aquellas que de un modo $\mathrm{u}$ otro giran en torno al degeneracionismo, higienismo, $\mathrm{y}$ genéricamente a lo que el mismo autor califica como eugenesia positiva ${ }^{2}$.

Baste por el momento decir que tal forma de entender la eugenesia se asienta sobre un modo singular de concebir la idea de raza, modo éste que se desliga del geneticismo materialista que sustentaba a la mayoría de prácticas eugenésicas del momento, para en su lugar reclamar para el espíritu una idea de raza que Vallejo hará coextensiva a la idea de Hispanidad que simultáneamente, como se verá, iba moldeando Maeztu. En este punto, hay que subrayar que la obra del autor preparó además el acomodo social de una de las instancias que integraban los dos órdenes biopolíticos que habilitaron al primer franquismo ${ }^{3}$, así el orden de los bienes -autarquía, sindicalismo vertical e intervencionismo-, y el orden de los cuerpos, cuyas instancias eran además de los seguros sociales y la beneficencia, la adhesiva y contagiosa política racial, que fue a la sazón catapultada empíricamente de la mano de Vallejo.

El manto científico, al cual se hizo mención más arriba, que procura la legitimación de la represión sobre el bando republicano se sostiene a partir de la básica dicotomía de orden médico, salud/enfermedad: así el autor reconstruirá experimentalmente 4 el carácter patológico de un otro republicano, demócrata, marxista y ateo, frente a su sana contrafigura consistente en un previo y racial nosotros inmerso en la tradición, el patriotismo religioso y atravesado por la Hispanidad.

La investigación que encabeza el comandante Vallejo Nágera, tiene como punto de partida, tal y como ha señalado Rafael Huertas en uno de los más relevantes textos ${ }^{5}$ que examinan la cuestión que consideramos, tres postulados preliminares: en primer lugar, el establecimiento de las relaciones entre la personalidad biopsíquica y la predisposición constitucional al marxismo; en segundo lugar, determinar la proporción del fanatismo marxista entre los inferiores mentales; y en tercer y

La serie de artículos publicada por Vallejo Nágera entre los años 1938 y 1939 y que lleva por título genérico "El Psiquismo del fanatismo marxista" o bien "Biopsiquismo del fanatismo marxista", serán los escritos del autor más citados y estudiados en relación a este aspecto de su obra. Hay que hacer notar que vieron la luz casi simultáneamente en dos revistas médicas, Revista Española de Medicina y Cirugía de Guerra y Semana Médica Española.

2 El significado confuso de esta expresión -tal cuestión se analizará en la parte II de este artículo- no debe, a su vez, deformarse con el que posee en la actualidad una vez constituido el campo de la biología molecular que canaliza el diagnóstico y la intervención genética: eutelegéneisis, clonación, partenogénisis. Cf. J. Habermas, El futuro de la naturaleza humana ¿Hacia una eugenesia liberal?, Barcelona, Ed. Paidós, 2002.

3 Véase al respecto S. Cayuela, Por la grandeza de la patria: La biopolítica de la España de Franco, Madrid, F.C.E., 2014.

4 La antedicha reconstrucción psiquiátrico-experimental la confeccionará Vallejo en el ejercicio de sus funciones como Jefe de los Servicios Psiquiátricos Militares del ejército franquista, y más concretamente en tanto que Director del Gabinete de Investigaciones Psicológicas de los Campos de Concentración de Prisioneros.

5 R. Huertas, "La Psico-biología del marxismo como categoría antropológica en el ideario fascista español", LLUL 19 (1996), p. 114. 
último lugar, determinar igualmente la proporción de psicópatas antisociales entre la masas marxistas. Sin duda, la sombra de la obra de Lombroso parece cernirse sobre algunos de estos postulados, no obstante, Vallejo ampliará el campo del análisis, y así sustituirá y superará la antropometría lombrosiana para en su lugar esgrimir las tesis del psiquiatra alemán Ernst Kretschmer, las cuales armonizan correlativamente la constitución corporal del sujeto con su temperamento y carácter. Así este autor propugnó distinguir entre tres fundamentales biotipos constitucionales ${ }^{6}:$ pícnico, $^{2}$ leptosomático y atlético; la primera figura corporal o biotipo la relacionó con el temperamento ciclotímico (variabilidad en el estado de ánimo), la segunda con el temperamento esquizotímico (introversión, timidez), y el tercer biotipo con el temperamento enequético (viscosidad afectiva); reservó un cuarto biotipo, displásico, para referirse a las formas extremas o degeneradas de los tres anteriores, o bien a sus posibles y particulares mezclas.

El aparato experimental del estudio de Vallejo sobre el fanatismo marxista se vertebró en torno a la biotipología kretschmeriana, que se acompañaba de un complejo cuestionario denominado Psicobiograma de Kretschmer, además hizo uso del llamado test diagnóstico para la introversión y extroversión de Neymann-Kohlstedt, incluyendo además el test de Marston-Mira, y sumando a todo lo anterior la medida del coeficiente intelectual mediante el método de Yerkes. Abundando en la cuestión, el autor seleccionó como sujetos experimentales sobre los que volcar todo este artefacto cientifico-experimental, por un lado, a un conjunto heterogéneo de prisioneros de guerra pertenecientes a las Brigadas Internacionales y cautivos en el campo burgalés de San Pedro de Cardeña, y de otro lado, a un grupo de cincuenta "prisioneros hembras", internas en la cárcel de Málaga.

Es necesario comentar que existe un notable desequilibrio entre el despliegue experimental exhibido por Vallejo y los exiguos resultados que a la postre fueron obtenidos. Después de corroborar las correlaciones ya conocidas entre los biotipos kretschmerianos y el temperamento ciclotímico, esquizotímico y enequético, el autor pasa a referir los resultados más sesgados y sugestivos de la investigación, esto es, aquellos que estando fuera del rango de la práctica científica dan soporte a la legitimación ideológica de la represión franquista. En este orden de cosas, y entre otros corolarios, el psiquiatra palentino criba a los distintos prisioneros en dos categorías diferenciadas: los revolucionarios natos y los imbéciles sociales. Los primeros son descritos por el autor del siguiente modo:

Aquellos sujetos que inducidos por sus cualidades biopsíquicas constitucionales y tendencias instintivas, movilizadas por complejos de rencor y resentimiento, o por fracaso de sus aspiraciones, propenden, en cierto modo congénitamente, a trastocar el orden social existente. Entre los revolucionarios natos incluimos a los esquizoides místicos políticos?

Mientras, los imbéciles sociales, se explica más adelante, serían una muchedumbre de torpes, seres influenciables, sin espontaneidad ni iniciativa, en definitiva, una masa anónima y casi bárbara. De tal modo, Vallejo venía a concluir que en el "material humano" investigado por él se hallaba una mayoría de sujetos que carecían de sindéresis

Cf. E. Kretschmer, Constitución y carácter, Barcelona, Labor, 1961. Obra original de 1927.

A. Vallejo Nágera, "Psiquismo del fanatismo marxista", Semana Médica Española, 1938, p. 147. 
efectiva y, por lo mismo, de cultura política alguna, asimismo, buena parte de entre ellos desarrollaban temperamentos degenerativos, todo lo cual, unido al ateísmo y la irreligiosidad, les convertía en proclives secuaces fanáticos de doctrinas tan elementales y simples como el marxismo. Hay que matizar que a lo largo de todo el estudio, y tenida en cuenta su obra por extenso, el autor tan solo acierta a adjetivar a bulto la obra de Marx, de ninguna manera su perspicacia política alcanza, vaya por caso, a distinguir entre antifascistas y marxistas, tanto es así que a los brigadistas estadounidenses sujetos al estudio y que se reclamaban miembros del partido demócrata, se les adjudicó militancia en un partido comunista. Los alcances políticos del autor no eran muy distintos de los que atesoraba cualquier otro oficial africanista como él.

Pues bien, como antes se afirmó, para erigir semejante reconstrucción ${ }^{8}$ de un otro malsano a causa de ser cientificamente rojo, marxista y ateo, fue menester que Vallejo Nágera dibujara con anterioridad la benéfica y salubre figura de un nosotros instalado en la religiosidad, la tradición y la generatriz idea de Hispanidad. La cuestión es que el tal nosotros fue adquiriendo cuerpo y sedimentándose a la par que nuestro autor, desde el inicio de la década de los años treinta del pasado siglo, comienza a interesarse por el estudio de la prácticas eugenésicas. Se internará así en un campo que, a finales de la década de los años veinte, contaba en España con numerosos y entusiastas practicantes, de ahí que en 1928 ya quepa detectar los primeros movimientos que alientan la institucionalización de la eugenesia en nuestro país. En tal año se inauguró en la Facultad de Medicina de la Universidad Central el Primer Curso Eugénico Español; no obstante, su desarrollo fue desbaratado por la presiones de la jerarquía eclesiástica plasmadas en la prensa diaria, y que hicieron mella en el régimen de Primo de Rivera dando lugar, en último término, a la interrupción del Curso mediante un Real Decreto Ley. De cualquier modo, el desmán gubernativo no hizo más que acelerar el crecimiento del número de publicaciones relacionadas con la eugenesia ${ }^{9}$, será justamente a este caudal de literatura eugénica al que Vallejo se va a incorporar dando a la imprenta sus obras más aquilatadas una vez sean finiquitadas la dictadura y la monarquía.

Apenas dos semanas después de que Maeztu publique en Acción Española su inicial artículo en defensa de lo hispánico, "La Hispanidad”, Vallejo Nágera publicará también, y en la misma revista -todo lo cual no deja de ser sintomático en orden a lo que se irá argumentando-, un escrito que le sitúa con claridad en el ámbito de la eugenesia. Su título así lo refleja sin ambages: "Ilicitud científica de la esterilización eugénica" ${ }^{10}$. El artículo no va a consistir, como su título deja entrever, en una tematización de lo que su autor entiende por eugenesia, sino que, antes bien, se va a desenvolver como una suerte de labor de mina frente a lo que otros, quizá la mayoría, entienden por tal práctica. La concepción eugénica general pasa por ser científica a fuerza de presentarse en tanto que materialista y racionalista, siendo por ello asimismo afín a la esterilización, cuando el asunto debe entenderse, a ojos de Vallejo, en sentido inverso, esto es, a fuer de ser racionalista y materialista la eugenesia se desprende de su cientificidad para incurrir en mera inhumanidad.

\footnotetext{
Véase R. Vinyes, “Construyendo a Caín. Diagnosis y terapia del disidente: las investigaciones psiquiátricas militares de Antonio Vallejo Nágera con presas y presos políticos”, Ayer 44 (2001), pp. 227-250.

Véase A. Ferrándiz y E. Lafuente, "El pensamiento eugénico de Marañón”, Asclepio LI:2 (1999), pp. 133-148.

10 A. Vallejo Nágera, "Ilicitud científica de la esterilización eugénica", Acción Española, 1:2 (1932).
} 
En las primeras páginas del texto se exhiben algunos contenidos de doctrina católica que parecen verificar la congruencia de la tesis del autor. Allí tanto se apela al Derecho Natural, coextensivo a la ortodoxia de Roma, como a la reciente encíclica, publicada en 1930, del Papa Pio XI, Casti Connubii:

La aplicación de utópicos principios eugénicos, con merma de los más sagrados derechos morales y físicos repugna a los espíritus no endurecidos por un bárbaro racionalismo. La Ciencia jamás puede contradecir al Derecho Natural, y, en realidad no existe pugna cuando se meditan detenidamente los resultados de la experimentación científica. Sacrificar unos hombres en beneficio de otros hombres constituye un principio farisaico inadmisible en los pueblos civilizados ${ }^{11}$.

El artículo se encuentra en la estela de la encíclica de Pio XI ya mencionada, pero también la encíclica se convierte en un baluarte argumental muy estimable para el autor, así hará uso de la misma frente a las tesis del Dr. Mayer, sacerdote y profesor de la Universidad Católica de Friburgo, que de un modo harto inconveniente había defendido, aportando argumentos de Tomás de Aquino, que la Iglesia en nada se opone a la esterilización de determinados psicópatas; al respecto, el autor afirma lo que sigue:

La Iglesia católica ha defendido oficialmente su actitud en la reciente Encíclica sobre el matrimonio cristiano [...] Consígnase expresamente que los magistrados públicos carecen de potestad directa sobre los miembros de sus súbditos. No puede lesionarse la integridad corporal porque el juicio humano nunca debe castigar a nadie sin culpa según enseña Santo Tomás de Aquino. Muy oportuna esta cita de la Encíclica, por basarse Mayer también en la autoridad del Santo para defender la esterilización desde el punto de vista católico ${ }^{12}$.

Así, una vez sentadas las bases de la refutación doctrinal católica de la eugenesia esterilizante, el palentino se explaya en lo que resta del escrito en la tarea, por un lado, de derruir o realzar las legislaciones que han venido surgiendo para regular tal biopolítica eugenésica en América y Europa, y, por otra parte, en discriminar entre las distintas e inhumanas modalidades de la esterilización eugénica. Ilegítimas son a su parecer las esterilizaciones por causa terapéutica, económica y penal o represiva. En este sentido, Vallejo se enzarza con ahínco contra los EE.UU ${ }^{13}$ apuntando hacia el Estado de Michigan, que ya en 1897 legisla a favor de la esterilización terapéutica de imbéciles y criminales reincidentes y, asimismo, refiriendo que el Estado de California en 1909 da por buena la esterilización terapéutica y penal en casos de violación, y también en aquellos otros que atañen a penados a perpetuidad que manifiestan depravación moral o sexual. Por el contrario, y en general, el autor se encuentra más cómodo con las leyes promulgadas en Europa, en especial con la ley sueca que sin ser insuperable sí ampara, vaya por caso, con criterio más benevolente, la prohibición del matrimonio entre enfermos psíquicos graves.

\footnotetext{
Ibidem, p. 142.

Ibidem, pp. 143 y 144.

"La psicología peculiar de los norteamericanos, o mejor dicho, el materialismo triunfante en una sociedad de formación moral imperfecta, nos explica el rápido desenvolvimiento de la ley de esterilización eugénica, que si unas veces busca el mejoramiento de la raza, otras se aplica como castigo, sin faltar Estados en los que se introduce como medida de economía”. Ibidem, p. 150.
} 
Por otro lado, no cabe olvidar que el escrito contiene también lo que por entonces son escuetas alusiones a factores que más tarde devendrán los goznes de la eugenesia positiva o de la Hispanidad de Vallejo, así no deja de mentar a la raza hispánica ${ }^{14}$, y a la eugamia ${ }^{15}$ en tanto que estructura fundante de la eugénica.

Dichas escuetas alusiones comenzarán a cobrar carta de naturaleza en Higiene de la raza: La asexualización de los psicópatas $^{16}$, obra publicada por Vallejo en 1934 que va a hacer las veces de puente hacia el conjunto de obras -que se sumarán a la detonación de la propaganda franquista durante la contienda- en las que ya se ofrecen talladas las ideas fuerza del proyecto eugénico del autor. La obra consiste en su sustancia en matizar cuestiones que habían sido abocetadas en el artículo ya comentado de 1932. Vallejo volverá a persistir en la impertinencia científica de las prácticas de asexualización o esterilización eugenésica de psicópatas o tarados psíquicos, pero su argumentación no adquirirá ahora tintes morales o piadosos, sino, bien al contrario, se deducirá, según su juicio, del estudio empírico de la naturaleza de la herencia y de la casuística psiquiátrica. Así examinará entidades nosológicas concretas, ya sean, por ejemplo, las psicosis maniaco depresivas o las psicosis endógenas características del sexo débil; sin embargo, tales indagaciones no aportan, lo que podía presumirse, el necesario soporte experimental que haga plausible la indeseada asexualización. Con respecto al estudio empírico de la lógica interna de la herencia, el autor incide en que la heredabilidad de las enfermedades psíquicas que poseen carácter recesivo ilegítima científicamente a la esterilización eugenésica:

Las dificultades del pronóstico hereditario empírico y la demostración de la recesividad de la herencia psicopatológica nos demuestran la absurdidad de imponer la esterilización a una persona porque haya padecido una enfermedad mental, pues puede suceder, y ocurre en realidad, que en su descendencia no vuelva a manifestarse el carácter patológico hasta los bisnietos o tataranietos ${ }^{17}$.

Al respecto, hay que destacar que más adelante el autor se mostrará incondicional partidario de la prohibición del matrimonio en el caso de los tarados psíquicos que transmiten indefectiblemente su enfermedad por heredarse la misma con carácter dominante ${ }^{18}$.

Por otra parte, en este escrito se abunda también en el envite de Vallejo en favor de la eugamia, así ésta será más firmemente aprehendida desde un doble enfoque científico y religioso que llega aparentemente a cuajar, a ojos claro está del autor, en el seno de los distintos congresos de médicos católicos. En este orden de cosas, cita el autor algunos de tales encuentros distinguiendo de entre ellos el Congreso de Médicos Católicos alemanes que se realiza en Colonia en mayo de 1934; entre las conclusiones del mismo se halla la que sigue: "Sabemos que la

\footnotetext{
14 "Nos hallamos actualmente los hispanos en el acmé de una fiebre legislativa, momento que consideramos oportuno para estudiar la esterilización legal en todos sus aspectos, especialmente en el científico, y formar opinión sobre su licitud y beneficios que pueden reportar a nuestra raza”. Ibidem, p. 142.

15 "La verdadera eugénica consiste en apartar del matrimonio a los que no pueden cumplir sus fines." Ibidem, p. 147.

16 M A. Vallejo Nágera, Higiene de la raza. La asexualización de los psicópatas. Madrid, Editorial Medicina, 1934.

17 Ibidem, p. 64.

18 Cf. A. Vallejo Nágera, Política racial del nuevo estado, Editorial Española, San Sebastián, 1938.
} 
verdadera eugenesia no puede tener un programa limitado a la esterilización de los anormales, y que la eugenesia es imposible sin la solución del problema social. Los más imperiosos deberes de la eugenesia residen en favorecer positivamente las familias numerosas y protegerlas mediante una legislación adecuada"19. El autor, a continuación muestra los católicos límites que deben acotar igualmente a la práctica eugámica, no sin antes hacer una breve y equívoca excursión alrededor de la eugenesia nacionalsocialista ${ }^{20}$.

El diario oficioso pontificio se ha ocupado en el pasado mayo de los peligrosos proyectos eugenésicos del Gobierno alemán racista, traslucidos en algunos trabajos publicados en la prensa diaria. [...]. En lo que respecta al certificado prematrimonial, la Iglesia condena toda limitación civil del derecho al matrimonio, sin que por ello se oponga a un certificado médico con fines meramente informativos. [...] La autoridad civil no puede impedir el matrimonio basada en un certificado médico ${ }^{21}$.

Todos los contenidos que hemos venido desgranando y que se alojan, entre otros, en los dos textos comentados, van a devenir figuras ya enterizas en el conjunto de obras firmadas por Vallejo que verán la luz durante el transcurso de la Guerra Civil. Se tratan éstas de libros breves que cumplen con las exigencias propagandísticas del momento. Las ideas centrales que albergan dichos escritos -hispanidad, raza, eugamia, etc.- reverberan con mayor o menor intensidad cruzándose entre los escuetos apartados que suelen componer su formato. Entre la brevedad y la repetición Vallejo Nágera tejerá un entramado de ideas que encauzarán no solo los concretos mecanismos de la biopolítica racial del régimen, sino que además compondrán una suerte de ideario franquista de la segregación ${ }^{22}$.

El mentado entramado de obras se compone por las ya citadas "Psiquismo del fanatismo marxista", Eugenesia de la Hispanidad y regeneración de la raza y Política racial del nuevo estado; a ellas hay que enlazar Eugamia: selección de novios, El factor emoción en la nueva España y Divagaciones intrascendentes. De tal inventario la primera en ser publicada durante este periodo, Eugenesia de la Hispanidad y rege-

\footnotetext{
19 Ibidem, p.108.
}

20 La fecha en la que discurre el Congreso de Colonia, año 1934 -el mismo año en que se publica el texto que comentamos- no deja de llamar la atención en tanto que el gobierno alemán promulgó el 14 de julio de 1933 la Ley para la Prevención de Descendencia con Enfermedades Genéticas. Quedaban sujetados a tal legislación los individuos de ambos sexos que padecieran alguna de las siguientes patologías: debilidad mental, esquizofrenia, trastorno maniaco depresivo, epilepsia genética, corea de Huntington, ceguera genética, sordera genética, deformidad física severa y alcoholismo crónico. A lo anterior se añadió la Ley de Peligrosidad Social y Medidas para Atajarla de noviembre de 1933, por la que se ampara y ensancha la esterilización prevista en la Ley de julio a los psicópatas antisociales: homosexuales, comunistas. etc. Al respecto, Vallejo después de haber reprobado, en 1932, la inhumanidad de las leyes eugénicas norteamericanas cuyo origen provenía de la imperfección moral del pueblo estadounidense, guarda ahora silencio en relación a las leyes alemanas de 1933, sin siquiera advertir de la existencia de las mismas en este contexto, y en su lugar dirige un calculado reproche indirecto sobre las leyes alemanas por venir; sin embargo, en las leyes de 1933 ya se constataba la apabullante biología aplicada en la que, en buena medida, se sustentaba la acción del gobierno nacionalsocialista. En realidad, las aludidas leyes de 1933 vienen a ser un fangal de geneticismo y biologicismo arbitrarios que en buena lógica el católico Vallejo Nágera hubiera debido desaprobar sin vacilación. Lejos de ello, y como se apreciará más tarde, el autor hallará interesadas y triviales similitudes de compromiso entre su obra y la eugenesia nacionalsocialista.

21 Ibidem, pp. 110-111.

22 Consultar al respecto el apartado "Eugenesia, el proyecto punitivo de la segregación total” en el artículo ya citado de R. Vinyes, "Construyendo a Caín. Diagnosis y terapia del disidente: las investigaciones psiquiátricas militares de A. Vallejo Nágera con presas y presos políticos”, Ayer 44 (2001), p. 236 y ss. 
neración de la raza, es también en la que mejor se encajan y despliegan los concisos bosquejos de las distintas ideas fuerza que remata el autor.

El libro publicado en 1937 -el prólogo data de marzo de 1936; la causa que motivó el retraso, según nos explica el mismo Vallejo, la premura por incorporarse al glorioso Movimiento $\mathrm{Nacional}^{23}$ - abre de inmediato puertas y ventanas para exhibir el desasosiego de su autor: el medio ambiente hispano, horadado por la degeneración y el cretinismo racial, parece llegar a su ocaso; al respecto se lamenta el palentino: "Contemplamos el panorama nacional profundamente doloridos [...] la triste realidad es que increméntase más cada día el cretinismo racial iniciado en las postrimerías de la dinastía austríaca, hallándonos al borde de la desaparición de la raza a partir del último heroico esfuerzo de la guerra napoleónica." ${ }^{24}$. Ya más dispuesto Vallejo pasa a delinear, en el apartado XXXIV del libro, los contornos de esa idea de raza que pareciera extinguirse sin remedio por lo que atañe a nuestra nación. La misma no es, tal y como pretenden los intelectuales darwinistas-materialistas, fruto de meros cruces biológicos que gracias al aislamiento endogámico vendría ahora a conservarse en precaria pureza; antes bien, el autor se adhiere, según asevera, a las tesis de Spengler que hacen oídos sordos a la grotesca terminología que contempla la posibilidad de tal raza pura, lo realmente sustancial no es la pureza de raza sino la raza fuerte que es capaz de integrar al pueblo, a la nación. Y continuando en el mismo sentido añade el autor el sobresaliente giro que caracteriza a su singular perspectiva racista:

Al hablar nosotros de raza, nos referimos a la raza hispana, al genotipo ibérico, que en el momento cronológico presente ha experimentado las más variadas mezclas a causa del contacto y relación con otros pueblos. Desde nuestro punto de vista racista, nos interesan más los valores espirituales de la raza, que nos permitieron civilizar tierras inmensas e influir intelectualmente sobre el mundo. De aquí que nuestro concepto de la raza se confunda casi con el de la "hispanidad". [...] En la raza ibérica no existe unidad en el biotipo, y así el vasco nos ofrece una figura corporal, un temperamento y un carácter que le hacen muy distinto del andaluz, del catalán, del gallego y del castellano. Pero la raza ha rebasado los límites territoriales y ha poblado o repoblado muchas naciones americanas, infundiéndoles no solamente caracteres biológicos, sino ideas, hábitos, idioma, religión y cultura, de manera que el argentino, el peruano, el chileno, el mejicano, ofrecen tales semejanzas con el castellano, por ejemplo, que podemos hablar de unidad racial. Empero repetimos que no hemos de dar importancia ni al ángulo facial ni al color de la piel, porque lo que llamamos raza no está constituido exclusivamente por las características biológicas que pueden transmitirse al través del plasma germinal, sino por aquellas que son luz del espíritu, como el pensamiento y el idioma ${ }^{25}$.

Por lo tanto, el acarreo de la raza lo constituyen ideas, hábitos, idioma, religión y cultura, en cuentas sumarias pensamiento e idioma. En el caso de la raza hispana la forma de tal herencia espiritual ya fue detectada por el sacerdote vizcaíno Zacarías de Vizcarra al transmutar el Día de la Raza en el Día de la Hispanidad, feliz mutación y expresión que retoma, como es bien sabido, el vitoriano Maeztu, para erigirse él mismo, y en palabras de Vallejo, en el paladín de la Hispanidad. Hay que recordar, ya

\footnotetext{
23 A. Vallejo Nágera, Eugenesia de la Hispanidad y regeneración de la raza, Burgos, Editorial Española S.A., 1937, p. 5.

24 Ibidem, p. 7.

25 Ibidem, p.108. Las cursivas son nuestras.
} 
que es un aspecto sobresaliente de la introducción de la obra de Vallejo en América Latina, que el mentado Zacarías de Vizcarra ejercitó funciones de censor en la revista argentina Criterio, la cual fue un puntal crucial en la pugna por moldear la eugénica argentina desde un prisma nacional católico - tal cuestión será tratada por extenso en la parte II de este artículo.

El palentino cita y recoge contenidos de los veintitrés artículos de Maeztu aparecidos en Acción Española, y que en 1934 se publican bajo el consabido título de Defensa de la Hispanidad. Si bien es cierto que la idea de Hispanidad, a ojos de Maeztu y Vallejo, comprende y caracteriza a la totalidad de los pueblos hispanos, también lo es que la idea de Patria es distinta pero indiscernible de la primera, a la vez que ésta también se acomoda del mismo modo con la idea de Raza. Así, cabría sugerir que, a nuestro entender, la Hispanidad es una suerte de idea de factura bifaz compuesta espiritualmente por la Patria y la Raza, "Mantiene el patriotismo el espíritu racial. El espíritu racial es aquella parte del espíritu universal que nos es asimilable [...]. La raza es espíritu, España es espíritu, la Hispanidad es espíritu. Perecerán las razas, las naciones y los pueblos que por extranjerizarse no sepan conservar su espíritu"26.

De cualquier modo, la Hispanidad espiritualmente amalgamada es tal en la medida en que se enhebra con el ideal católico ${ }^{27}$ que, por ejemplo, en su momento le infundió San Isidoro. Nuestra raza ha podido obrar como imperialista mediando la guía de una Monarquía Católica que movilizó, entre otros principios, los frutos de la también católica teología jurídica elaborada por Vitoria; así reaparece esta idea fuerza en otro libro de 1938:

\begin{abstract}
Nuestra raza no está caracterizada por índices antropométricos, sino por índices biopsíquicos, los cristianos que forjaron el espíritu de la Hispanidad. Hemos de impregnarnos del espíritu de la Hispanidad, tal como la concebía el llorado Maeztu, para comprender nuestras esencias raciales y diferenciar nuestra raza de las extrañas. Las ideas paganas, las materialistas y las racionalistas adheridas a nuestra raza, son las culpables de su degeneración, los parásitos que la aniquilan ${ }^{28}$.
\end{abstract}

De cualquier modo, resulta acuciante, y todavía más en 1937, combatir a ideas y parásitos paganos, lo cual supone estimular la regeneración de la raza y la patria, luchar en fin por la Hispanidad misma, para ello es necesario desbrozar el camino y comprender que tal renovación debe transitar por la vía del perfeccionamiento del espíritu, esto es, por la senda de la eugénica de cualidad positiva, dejando así de lado la eugenesia negativa y esterilizante que ensalzan y favorecen los países de organización estatal y marxista: "A nuestro entender, para impulsar la regeneración de la raza, mejor que selección de los biotipos, perfeccionamiento de los fenotipos [...] En esta acción consiste la eugenesia positiva, pues otra es materialmente imposible, y más imposible todavía reglamentar la reproducción de los humanos como la de los animales." ${ }^{29}$ Ahora bien, ello no es óbice para que Vallejo Nágera también coincida

26 A. Vallejo Nágera, Eugenesia de la Hispanidad y regeneración de la raza, Burgos, Editorial Española S.A., 1937 , p. 114

27 El peso del catolicismo y la interpretación del mismo en la obra del autor se puede calibrar, por ejemplo, acudiendo al título y al contenido de un apartado de sus textos: "Pro-Inquisición", publicado en Divagaciones intrascendentes, Valladolid, Talleres Tipográficos Cuesta, 1938, p. 106.

28 A. Vallejo Nágera, Política racial del nuevo estado, San Sebastián, Editorial Española, 1938, p. 16.

29 A. Vallejo Nágera, Eugenesia de la Hispanidad y regeneración de la raza, Burgos, Editorial Española S.A., 
con el punto de vista eugenésico nacionalsocialista, imponiendo "una política que neutralice el daño que puede venirle al plasma germinal de los agentes patógenos, tanto físicos como psíquicos, materiales como morales. Coincidimos con los nacionalsocialistas en que cada raza tiene un significado cultural particular, y unas características biopsíquicas." 30 . Invitamos al lector a la lectura de la nota veinte de este artículo.

Justamente, Vallejo abogará por retener las características excelsas de la raza hispana, y sin negar la mezcla entre castas superiores e inferiores, pretenderá que la acción de la política racial se oriente en favor de la constitución de una "supercasta hispana", que sea distinguible por su robustez moral y vigor espiritual. Ahora bien, la naturaleza positiva y ambientalista de la eugénica del autor, conlleva que la regeneración de la raza transite, entre otras medidas, por la selección de matrimonios ${ }^{31}$ y el aumento sostenido de la población; éste último factor supone que todas las clases sociales se reproduzcan proporcionalmente con el fin de que se mantenga el equilibrio en la trasmisión de los valores raciales. Se impone así poner en marcha una radical reforma social que mejore las condiciones ambientales en las que se reproducen los individuos inferiormente dotados; aun estando en contra de la eliminación de los tarados, se niega "que la higiene racial deba impulsar denodadamente la procreación de los inferiores. Pero tampoco hemos de limitarnos a estimular la fecundidad de los selectos. Nuestro programa tiende a despertar en los individuos de todas las clases sociales un deseo de ascender a las jerarquías selectas".32.

A su vez, y enlazado con los anteriores, un factor también determinante de la regeneración de la raza en la Nueva España, es la regeneración de la institución familiar. Ésta, en efecto, debe adherirse a los principios tradicionales de la moral cristiana, ya que la misma es un bastión contra la corrupción del entorno, a la vez que cauce inmejorable de la tradición. La cultura y la religión consustanciales a la familia católica, hacen que ésta vuelque sobre el ambiente un influjo moral que vigoriza y cimienta los valores raciales. En virtud de todo ello, y a ojos del palentino:

Constituye un deber de todo buen ciudadano, consciente de la responsabilidad moral de su destino histórico crear una familia, si tiene capacidad y salud para ello. Es el solterón, por regla general, un mal patriota y un mal ciudadano, o un enfermo. Piensen los solterones seriamente sus deberes para con Dios, la Patria y el Estado y confirmarán el precedente aserto [...] El ciudadano modelo de la Nueva España será casado y prolífico ${ }^{33}$.

En otro orden de cosas, y antes de concluir esta primera parte del artículo, queremos señalar que Vallejo lleva a cabo un ensanchamiento del campo de batalla ideológico y de propaganda al hilvanar las ideas ya construidas por medio de una nueva sutura, la psicología de las masas y las multitudes (Le Bon, Freud). Así en El factor emoción en la España nueva, ${ }^{34}$ considera a las masas como portadoras de complejos

1937, p. 77.

$30 \quad$ Ibidem, p. 116.

31 A. Vallejo Nágera, Eugamia: selección de novios, San Sebastián, Editora Española S.A., 1938.

32 A. Vallejo Nágera, Eugenesia de la Hispanidad y regeneración de la raza, Burgos, Editorial Española S.A., 1937, pp.117-118.

33 A. Vallejo Nágera, Política racial del nuevo estado, San Sebastián, Editorial Española 1938, p. 55.

34 A. Vallejo Nágera, El factor emoción en la España nueva, Burgos, Federación de Amigos de la Enseñanza, 
psicoafectivos que según su naturaleza dan lugar a reacciones edificantes o destructivas; la cuestión consistirá en domeñar tales complejos dosificando emociones y sentimientos por medio de la sugestión: "Cierto es que resulta peligroso sembrar sentimientos con preferencia a ideas, aunque aquéllos se desprenden de las últimas; pero es el único camino viable cuando se trata de masas, si quiere lograrse resonancia afectiva en las muchedumbres y unificarlas disciplinadamente para la acción"35.

Desde la atalaya de la psicología de las multitudes se pueden detectar los complejos psicoafectivos pertinentes para la reconstrucción de una España grande: la religiosidad, el patriotismo, la responsabilidad moral; en este contexto el Movimiento Nacional es reacción popular a los complejos disolventes y autodestructivos de la Patria: "Surgió el Movimiento nacional del deseo del verdadero pueblo español de recuperar sus valores universales, aherrojados por el materialismo marxista, y, conjuntamente, de la necesidad de salvar la honra de España ante el mundo"36. Enemigos del Movimiento son los complejos de ínfima calidad, así el resentimiento, el rencor, la inferioridad, la emulación envidiosa, el arribismo ambicioso y la venganza.

En el último apartado del texto, La sonrisa del Caudillo, el autor, acogiéndose a lo argumentado en otros escritos, vuelve a dar cuenta de la estrechísima relación existente entre la figura corporal y las cualidades psicológicas. Más precisamente, nos viene a decir que los complejos psicoafectivos antedichos también se materializan en rostros y volúmenes corporales; así, la degeneración física, las deformaciones corporales, la fealdad, se encuentran ligadas a complejos de rencor y resentimiento; mientras que, por otro lado, la armonía de las dimensiones del cuerpo y la belleza física se corresponden con el alma noble y virtuosa. La constatación paradigmática de lo dicho se compendia en el contorno de la figura del cuerpo del Caudillo y en la sonrisa que define su rostro: "La sonrisa del Caudillo refleja el estado de ánimo de la nueva España [...] La comparación de las figuras corporales de nuestro invicto Caudillo y del llamado presidente de la II República española, recuerda y exterioriza las respectivas psicologías, cuyo encarecimiento podemos ahorrarnos" ${ }^{\prime 37}$.

Así pues, y como hemos venido examinando y argumentando, la eugenesia de la Hispanidad compuesta por Vallejo Nágera se desarrolla emparejada al desenvolvimiento de la idea misma de Hispanidad (Maeztu), la cual, tal y como se razonó, posee una estructura bifaz que se conforma por el carácter distinto pero indiscernible de la Raza y la Patria, relación ésta que queda engranada en el seno de la tradición de la religión católica. Es, precisamente, la dogmática de esta tradición interpretada al extremo la que justifica el frontal rechazo del materialismo geneticista que moldea a la eugenesia negativa esterilizante, siendo también la misma tradición la que permite erigir una alternativa que se cimienta, siguiendo a la ortodoxia de Roma, en mantener intacto el organismo de los individuos, al tiempo que se proyectan programas positivos de corte higienista que alcanzan tanto al ámbito de la eugamia, el impulso de la natalidad y la familia, como al contexto de la preselección de selectos o las campañas contra la neurastenia y la histeria. Cómo y por qué tales tesis encuentran acomodo en Latinoamérica es cuestión que pretendemos dilucidar en la segunda parte de este artículo.

1938.

Ibidem, p. 10.

Ibidem, p. 11.

Ibidem, pp. 29-30. 


\section{Introducción y resonancia del enfoque eugénico de Vallejo en Latinoamérica}

Antes de nada es obligado proporcionar al lector el contexto latinoamericano con respecto al tratamiento académico e institucional por parte de juristas y médicos (con el amparo de los gobernantes) de la cuestión eugénica en el primer tercio del pasado siglo en aquellos países que bien tanto por su súbita densidad demográfica, bien por su heterogeneidad racial a causa de las oleadas migratorias de principios del XX, o por ambos factores a la vez, fueron especialmente sensibles a esta temática en los años 20 y 30 del siglo XX (en Perú ${ }^{38}$ y Bolivia ${ }^{39}$ hay que esperar hasta casi la década de los 40 mientras que en Paraguay el interés por el asunto se dio mucho antes pero de un modo más descarnado y menos "clínico" y actualizada haremos una panorámica, pues, por el Caribe de las tres razas (Cuba, Colombia, Venezuela), México, Chile y, en último lugar, por Argentina, por ser este último país el lugar donde se produjo la recepción de las ideas de Vallejo Nágera (Brasil, a pesar de su gran relevancia ${ }^{41}$, no contaría, como es obvio dentro de la

38 La Primera jornada peruana de Eugenesia, habría de darse en Lima entre el 3 y el 5 de mayo de 1939. Parece pertinente mencionar esta reflexión de Enrique Gamio en La crónica médica de Lima, recogida de un artículo sobre la eugenesia en el Perú, quien, a la escasez demográfica de su país y el descuido en las leyes sobre inmigración, añade como causa de la "desperuanización” del Perú el que "mientras Argentina y Chile tienen un potencial étnico homogéneo, debido a los binomios raciales, derivados de su unión con italianos y alemanes, respectivamente el binomio mongolafricano ha producido excesos de hibridismo". Citado en W. Mendoza y O. Martínez, "Las ideas eugenésicas en la creación del Instituto de Medicina social", Anales de la Facultad de Medicina de la Universidad Nacional Mayor de San Marcos 60:1 (1999), p. 58 (cursivas nuestras). Frente a esta posición racista se encuentra la medicina social de Carlos Enrique Paz Soldán, tal y como también explican Mendoza y Martínez.

39 No tenemos noticia de tal tratamiento institucional en Bolivia hasta 1943, con la obra de L. Jiménez de Asúa, Cuestiones penales de eugenesia, filosofia y política, Imprenta Universitaria, Cochabamba, $1943 \mathrm{y}$, un año después, con la Semana Eugénica (véase de B. Carrasco, La Eugenesia en el ambiente boliviano. Talleres gráficos de Armando Gamarra y Cía., La Paz, 1945).

40 La guerra contra el Paraguay por parte de la Argentina (presidida por Mitre en el comienzo de la misma y por Sarmiento al final), el Uruguay y Brasil acabó, entre 1865 y 1871, con las tres cuartas partes de su población: "La "solución final" para los gauchos, negros, indios en general y también para el Paraguay, no se alejaba en demasía de la eugenesia negativa, cuyas medidas estaban destinadas a las clases bajas, con el objetivo último de hacerlas “desaparecer" [...]: "Estamos por dudar de que exista el Paraguay. Descendientes de razas guaraníes, indios salvajes y esclavos que obran por instinto o falta de razón. En ellos, se perpetua la barbarie primitiva y colonial... Son unos perros ignorantes... Al frenético, idiota, bruto y feroz borracho Solano López lo acompañan miles de animales que obedecen y mueren de miedo. Es providencial que un tirano haya hecho morir a todo ese pueblo guaraní" [Faustino Sarmiento, Carta a Mitre, 1872. Reproducido en El Nacional del 12 de diciembre de 1877]" Véase J. M. Silvero, Suciedad, cuerpo y civilización, Universidad Nacional de Asunción, 2014, p. 228.

41 No obstante, aunque fuera del ámbito de "la Hispanidad", por su importancia crucial, debe decirse algo en cierto extensión sobre el país iberoamericano que fue el primero en dar un tratamiento institucional a la cuestión eugénica. Los entonces Estados Unidos del Brasil habían atraído desde finales del XIX a una gran cantidad de inmigración procedente también de Europa (Italia y Alemania, principalmente) a causa del negocio del café. Las ciudades se masificaron, con las consecuencias previsibles que esto tiene en una economía de industrialización lenta y basada en el comercio de materias primas. En 1917 coincidiendo con la huelga general en Sao Paulo se produce la primera reunión de médicos para abrir el debate sobre la posibilidad del matrimonio consanguíneo y en este contexto, como relata Stepan, se aprovechó la oportunidad de la reunión para vincular el matrimonio con la eugenesia de Galton. Tras el congreso se propuso formalmente por vía epistolar la creación de una sociedad científica nueva dedicada específicamente a la nueva eugenesia e invitando a la participación de sus colegas: "El 25 de enero de 1919 nació la Sociedad Eugénica de Sao Paulo (Sociedade Eugénica de Sao Paulo). Su fundación representó el primer paso en la historia organizada de la eugenesia en América Latina y el comienzo de, en mayor o menor medida, una implicación continua de los latinoamericanos en la eugenesia desde 1918 hasta la década de los cuarenta." El número de miembros (la mayoría médicos) superaba con creces al de la Sociedad eugénica de Francia (ciento cuarenta frente a cien) y sólo dos carecían del título de doctor, un título que la mayor parte de las veces implicaba la graduación en la Escuela de Medicina y la de Derecho. Véase N. L. 
"Hispanidad"). El fin de esta panorámica es mostrar el estado complejo del asunto, la borrosidad del concepto "eugenesia latina" (cuestionado por Alexandra Stern así como por Marisa Miranda y Gustavo Vallejo) entendido como co-extensivo con la eugenesia positiva por Nancy L. Stepan -tal y como se explica a continuación-; borrosidad que contrasta con la clara definición, por su nacional-catolicidad, del concepto de "eugenesia de la Hispanidad" (un concepto que sólo pudo hallar plena cabida allende las fronteras de España en Argentina, por su coyuntura histórica durante los años 30 y las dos décadas posteriores).

En efecto, Nancy L. Stepan -en The Hour of Eugenics: Race, Gender and Nation in Latin America, obra que, como es reconocido incluso por sus críticos, roturó el campo de investigación en el que este artículo se enmarca- expone cómo optar por uno u otro tipo de eugenesia -negativa o positiva, según la forma de clasificación de aquellos que se alinean con la doctrina de la Casti connubii y del padre franciscano Agostino Gemelli ${ }^{42}$, quienes se adjudican el segundo de los adjetivos- venía a ser en los primeros treinta años del siglo XX un rasgo definitorio del sesgo ideológico progresista o derechista, respectivamente, lo cual resulta ya clamoroso en la representación que del asunto hacen sus protagonistas en la década de los treinta. En cualquier caso, tales sesgos se cruzan siempre con posiciones "científicas" y así el neolamarckismo ${ }^{43} \mathrm{y}$ el neodarwinismo libran su última gran batalla sobre el mismo campo de Marte científico donde ya Cuvier ${ }^{44}$ ganó para la teoría de las especies un primado ontológico que ya nunca recuperará la haecceitas de los individuos.

En Cuba tendría lugar la Primera Conferencia de Eugenesia y Homicultura (la siguiente sería en Buenos Aires, en 1934) a la que sucedería, a finales de 1927 o comienzos de 1928, la fundación de la Oficina Panamericana de Eugenesia y Homicultura con sede temporal en La Habana. Se trataba de un organismo científico oficial dirigido por un facultativo, presidente de la Academia de Ciencias Médicas, Físicas y Naturales de La Habana. Con el fin del machadismo en 1933 el académico al cargo se exilia a Miami y aunque la Oficina existió no devino en Instituto -tal y como se había proyectado ${ }^{45}$.

Stepan, The hour of eugenics: race, gender, and nation in Latin America, Cornell University Press, 1991, p. 47.

${ }^{42}$ Es menester recordar aquí brevemente la implicación que Gemelli tuvo en un episodio que afectó notablemente a quien fue la contrafigura de Vallejo Nágera durante los tiempos de la Guerra civil española: el republicano Emilio Mira. Acusado de haber colaborado con las checas por un grupo de psiquiatras catalanes, una vez que Mira ya se encontraba en el exilio, Gemelli, profesor de Psicología en Milán, le requirió una respuesta sobre la veracidad de las acusaciones y no quedando satisfecho con la misma las dio por veraces, publicándolas. Véase Emilio García García, Lucía Arburu y Helio Carpintero, "Las acusaciones contra Emilio Mira y López. Un episodio lamentable en la Historia de la Psicología", Revista de Historia de la Psicología 13:2-3 (1992).

43 Siempre que dejemos al margen del lamarckismo la teoría de la selección orgánica de Baldwin.

44 M. Foucault, "La situation de Cuvier dans l'histoire de la biologie", Revue d'histoire des sciences et de leurs applications, XXIII:1 (1970), pp. 63-92 (journées Cuvier, Institut d'histoire des sciences, 30-31 mai 1969)

45 Destacó hasta el momento la contribución intelectual previa del miembro de la Sociedad de Naciones y de la Unión Panamericana (sección de Higiene y Oficina sanitaria) Domingo Ramos con su obra, de 1924, Cuba en la higiene internacional y el finlaismo, para quien si bien la cuestión migratoria en relación con los cambios económicos era capital no lo era menos la constitución biológica y la calidad de la misma predominantes en el país. Su discurso fue ortodoxo, se amparaba en Weismann y consideró que las mejoras raciales no son resultado del mestizaje sino que es un proceso que cada raza y clase social debe realizar por separado. Llegó a ser crucial en su discurso la cuestión acerca de la capacidad de adaptación que las razas que llegaban tenían para adaptarse a los nuevos climas -todo ello en relación con la cuestión migratoria. La base de este pensamiento, en cualquier caso, ya estaba puesta desde 1909, cuando Francisco Menocal había ya planteado la necesidad de la eugenesia negativa en la Sociedad de estudios clínicos de La Habana, pidiendo que se impidiese legalmente la reproducción de los imperfectos y se legalizase la esterilización de enfermos y degenerados (el título del discurso de Menocal fue "La ley de inmigración debe enmarcarse en el principio científico de la selección como medio 
En cualquier caso, a partir de 1936, se abre el ángulo de contemplación del asunto en el sentido de que se pone el énfasis en las condiciones de vida y de trabajo y en el ambiente en general y tras 1938 la voz de Ramos deja de tener eco. Los jesuitas tenían su espacio en la educación de los bachilleres y en la concesión del Nihil obstat, atribución de, entre otros, Pelegrín Franganillo -quien se lo concedió al manual de Biología publicado por un tal Gustavo A. Caballero, donde se concluía que Lamarck, Darwin y Weismann habían sido refutados y cuyo título fue Evolución de los seres vivientes- "quien desarrolló el mismo discurso que, por ejemplo, los autores españoles conservadores y tradicionalistas de los años treinta, como el psiquiatra Antonio Vallejo Nágera"46.

En el Caribe colombiano, como explica Jason McGraw:

Los programas de higiene de comienzos del siglo XX se diferenciaban de los anteriores esfuerzos, porque esta vez eran intelectuales quienes contribuían a las ideas contemporáneas sobre eugenizar la raza. [...] La misma campaña anti-alcohol se entendía como parte de un esfuerzo más amplio para mejorar dicha raza, con la clase trabajadora como su principal objetivo ${ }^{47}$.

En efecto, si para los seguidores de Lamarck era posible la blastoftoria, es decir, que agentes tóxicos exteriores - que atacarían a las clases más bajas vía alcoholismo, tuberculosis, etc. - alteren el protoplasma germinativo, entonces la eugenesia ha de atacar, dentro de programas más amplios de salud pública alentados por un cierto paternalismo criollo-intelectual, el medio ambiente. Este paternalismo se dio también en el país vecino. En efecto, en la Venezuela de Juan Vicente Gómez no sería posible mantener el sistema de privilegios dentro del nuevo orden que la nueva era del petróleo hacía barruntar sin apelar a un mestizaje (científicamente controlado). Algo de lo que se percataron sus principales opositores, quienes orientaron el discurso pro-mestizaje en una determinada dirección política alternativa que fructificaría en el ascenso al poder de Rómulo Gallegos ${ }^{48}$.

En México, antes de la Revolución, la cuestión de la eugenesia estuvo relaciona$\mathrm{da}$, en clave de eugenesia positiva, con la necesidad de garantizar la preeminencia blanca, de modo tal que las políticas continuaran lo que ya de resultas de la "lucha por la vida" habría venido a ser: "Los blancos o los blanqueados prominentes como el mestizo Porfirio Díaz eran más aptos... ya que los indios habían de sucumbir en la lucha por la vida, por lo que la mejor forma de hacer progresar a México, era, por consiguiente, con colonos europeos"49. Sin embargo, tras una guerra revolucionaria de efectos devastadores, se dio una nueva imbricación reactiva entre darwinismo, eugenesia negativa y, esta vez, progresismo; Stepan:

de mejoramiento de la raza.")

46 A. García, R. Álvarez y C. Naranjo, En busca de la raza perfecta: eugenesia e higiene en Cuba (1898-1958), Editorial CSIC-CSIC Press, 1999, pp. 42-43.

47 J. McGraw (trad. De Marcela Echeverri), "Purificar la nación: eugenesia, higiene y renovación moral-racial de la periferia del Caribe colombiano, 1900-1930", Revista de Estudios Sociales 27 (2007), p. 63.

48 D. Yarrington, "Populist anxiety: race and social change in the thought of Romulo Gallegos", The Americas 56:1 (1999), pp. 65-90

49 Véase L. Suárez, "Evolucionismo y eugenesia en México", Boletín Mexicano de la Filosofía y Historia de la Medicina 12:1 (2009), p. 19. 
Ideológicamente, el socialismo, anticlericalismo y el materialismo de la revolución hizo a México receptivo a nuevos desarrollos en la ciencia y en el pensamiento social. Las ideas darwinianas fueron familiares y muchos biólogos mexicanos, tales como Alfonso L. Herrera, fueron evolucionistas convencidos y materialistas ${ }^{50}$.

Venustiano Carranza propuso al Congreso Constituyente una nueva ley sobre Relaciones familiares que permitiese por el bien de la especie, y complementando la selección natural con otra artificial que suavizase sus rigores, retirar el derecho a la reproducción a los incapacitados, sifilíticos y tuberculosos ${ }^{51}$. En cualquier caso, tal y como señala en otro lugar Stern, la eugenesia "era una teoría que la gente común y corriente podía aceptar y entender. Por ejemplo, los concursos regionales mexicanos que elegían la sinaloalense o la guadalupana más bella tenían sus presunciones acerca de la perfección biológica y fenotípica" ${ }^{52}$.

En Chile hubo acercamientos a la cuestión eugénica desde la derecha más dura y desde sectores progresistas. De lo primero da escandalizado testimonio el doctor Roberto Barahona en la Jornada Católica de Estudios Médicos de 1936, realizada en Santiago de Chile, quien se lamentó de la barbarie cavernaria que suponía apelar a Esparta como modelo de organización racial ${ }^{53}$. A esto se unió que como la esterilización eugénica constituyó "un problema no menor en las relaciones entre el régimen nazi y el Estado Vaticano, las intervenciones variaban su interlocutor en forma -a veces muy difícil de distinguir-, entre el nazismo y los médicos favorables a la anticoncepción y la esterilización en Chile." ${ }^{54}$ Los trabajos defendidos en el ámbito universitario chileno de las décadas de las que nos estamos ocupando hablan por sí solos ${ }^{55}$ pues en ellos se cita a Hitler (en el de

50 N. L. Stepan, The hour of eugenics: race, gender, and nation in Latin America, Cornell University Press, 1991, p. 55 (la traducción es nuestra). Stepan explica también cómo incluso feministas mexicanas estuvieron activamente implicadas en la eugenesia en Alemania y en otros lugares en los años veinte (tras la Gran guerra), preocupadas por la mortalidad y la salud materno-infantiles. Y aunque no fueron demasiado bien acogidas en Europa "en el México de 1921, sin embargo, el Congreso Mexicano de la Infancia planteó cuestiones eugénicas y sexuales; votó, incluso, en favor de la esterilización de los criminales -un presagio de la eugenesia más extrema que en un momento dado surgiría en México". Uno de los casos de esta eugenesia "más extrema" a los que refiere Stepan, lo encontramos bien documentado en un reciente artículo de Alexandra Minna Stern sobre lo acaecido en Veracruz a finales de los veinte y principios de los treinta: "Los archivos mencionan crípticamente algunas «operaciones» llevadas a cabo por médicos del estado. Aunque nunca sabremos si estas fueron ciertamente vasectomías o extracción de trompas de Falopio, es posible que fueran estas, dado que no fue inusual en otras partes del mundo ocultar las esterilizaciones bajo términos como «apendicectomía» o «histeroectomía» [...] Esta legislación hizo posible a la administración de Tejeda hacer uso del puño de hierro del estado en lo concerniente a la eugenesia preventiva en Veracruz, con el fin, por encima de todo, de controlar las vidas y los cuerpos de las trabajadoras del sexo" (la traducción es nuestra). En A. M. Stern, "The Hour of Eugenics" in Veracruz, Mexico: Radical Politics, Public Health, and Latin America's Only Sterilization Law", Hispanic American Historical Review 91:3 (2011), pp. 441-442.

51 L. Suárez, "Evolucionismo y eugenesia en México", Boletín Mexicano de la Filosofia y Historia de la Medicina 12,1:19-23 (2009), p. 20.

52 A. M. Stern, "Compilando y extendiendo la historia de la eugenesia en el mundo latino: avances y ausencias", Revista Estudios, número especial, mayo de 2012.

53 M. Sánchez, "Eugenesia: ciencia y religión. Una aproximación al caso chileno", Revista de Historia Social y de las Mentalidades 18:1 (2014), pp. 64-65.

$54 \quad$ Ibidem, p. 75.

55 Nos referimos a trabajos como el de Eduardo Pradel, Matrimonio civil y eugenesia (Memoria de prueba para optar al grado de Licenciado en la Facultad de Leyes y Ciencias Políticas de la Universidad de Chile, Santiago, 1926); el de Manuel Martín Álamos, La esterilización (Memoria de prueba para optar al grado de Licenciado 
1929) o se invoca al patriotismo como algo de lo que carecen quienes descuidan la higiene racial (en el de 1939) ${ }^{56}$.

Desde la izquierda, como expone Stepan, "el radical Frente Popular propuso una legislación más restrictiva para controlar las enfermedades venéreas; el director de salud pública del momento, el Doctor Salvador Allende, lo sugirió como proyecto de ley en el Congreso en 1939"57.

En Uruguay y en Argentina se rompe por alguno de los términos la dicotomía lamarckismo-progresismo-eugenesia positiva vs. darwinismo-derecha-eugenesia negativa. Esto es lo que han señalado Marisa Miranda y Gustavo Vallejo en numerosas publicaciones y en lo que Alexandra M. Stern ha profundizado con sus estudios sobre México: la tesis de que la "eugenesia latina" apostó regularmente por la línea higienista y de la selección matrimonial (positiva, anti-blastoftoria, lamarckiana) antes que por la de la esterilización (negativa, anti-descendencia, darwiniano-weismanniana) ni se cumple en todos los casos (véase México) ni puede interpretarse al margen de los conflictos con la Iglesia Católica, auténtico "tercero en discordia". Dada la imbricación entre la cuestión racial y la nacional, el enfoque nacional-católico de Vallejo tendrá cabida allí donde la institución romana mantiene influencia política efectiva y/o está en conflicto activo con las fuerzas gubernamentales. Veremos, en efecto, cómo en las tres ocasiones en que reaparece Vallejo Nágera en forma de cita o referencia textual en Argentina, siempre lo hace en función de su conveniencia casuística al momento que se vive en las relaciones con la Iglesia de Roma. Este no pudo ser, en cambio, el caso del Uruguay de la época ${ }^{58}$ (cuando este país devino en "la Suiza de América"), donde el laicismo prosperó, echó hondas raíces y no fue revertido quizá porque fue el resultado de un largo proceso que se había tomado ya todo el siglo XIX y que desembocó en el batllismo. Fue entonces, con el batllismo, que el discurso eugénico alcanzó su cénit. De hecho, incluso la idea de la esterilización fue durante las décadas de los veinte y los treinta dilatadamente discutida y planeó -como explica J. P. Barrán- por encima de la cabeza de médicos, juristas y políticos hasta los años 40, estando muy cerca de ser plasmada en forma de ley, pero

en la Facultad de Ciencias Jurídicas y Sociales de la Universidad de Chile, 1935) y el de Ernesto Hechenleitner, Herencia morbosa y su correctivo eugenésico: la esterilización (Memoria de prueba para optar al grado de Licenciado en la Facultad de Ciencias Jurídicas y Sociales de la Universidad de Chile, Santiago, 1936). El primero y el tercero se encuentran citados por Javiera Letelier en su tesina, defendida en diciembre de 2009, en la Universidad Alberto Hurtado, "Gobernar es poblar... Seleccionadamente". Ideas eugenésicas en Chile 1925-1941 y el segundo por Marcelo Sánchez Delgado, ’Eugenesia, ciencia y religión. Una aproximación al caso chileno", Revista de Historia Social y de las Mentalidades 18:1 (2014), pp. 59-83.

56 Posteriormente -siguiendo a Javiera Letelier- el discurso se suaviza: "Las citas de autoridad utilizadas para darle más fuerza a las ideas también abordaron el aspecto científico y una de las figuras más requeridas fue el médico eugenista Gregorio Marañón, quien por su libro “Amor, conveniencia y Eugenesia” de 1936 era catalogado como un insigne autor. También el médico Hans Betzhold, autor de "Eugenesia", editado y publicado en Chile y dedicado al Presidente Pedro Aguirre Cerda, fue comúnmente citado o a lo menos era alusión obligada en las bibliografías de las tesis sobre eugenesia a partir del año 1939". En J. Letelier, "Gobernar es poblar... Seleccionadamente”. Ideas eugenésicas en Chile 1925-1941. Tesina para optar al grado académico de Licenciada en Historia, defendida en diciembre de 2009 en la Universidad Alberto Hurtado de Santiago de Chile, Parte II, p. 2.

57 N. L. Stepan, The hour of eugenics: race, gender, and nation in Latin America, Cornell University Press, 1991, p. 126.

58 En efecto, Uruguay, a su escala, también llega a tener problemas migratorios, especialmente con la vivienda urbana en la capital, donde el hacinamiento en los "conventillos" -fruto de la especulación inmobiliaria- de las minorías étnicas que nutrían de soldados, pequeños comerciantes, lavanderas, obreros, jornaleros, etcétera, a Montevideo empezó a ser preocupante a partir de la segunda década del siglo XX. Muchos de ellos procedían de Europa. 
finalmente en su lugar acabó implantándose un proyecto de certificación prematrimonial ${ }^{59}$.

Como en Uruguay y siguiendo a Stepan, "en Argentina, la eugenesia fue asociada con la izquierda secular y moderna y con grupos anarquistas ${ }^{60}$, los cuales desempeñaron una parte importante en la vida cultural y política argentina en las dos primeras décadas del siglo XX" ${ }^{\prime 61}$ El caso argentino es el de una nación rica que atrajo a millones de inmigrantes, con una profesión médica regularizada, prestigiosa y organizada, que contaba con un gran número de facultativos entre sus miembros. Una profesión que fue especialmente escuchada por los dirigentes a causa de las epidemias y enfermedades endémicas, relacionadas en gran medida con los flujos migratorios: "la mejora en las tasas de mortalidad y las ratios de morbidad puso a Buenos Aires por delante de Nueva York en las estadísticas sobre salud" ${ }^{2}$. Un año después del primer golpe de Estado contra la Argentina constitucional de 1930 (cuya causa se cifra en la nacionalización del petróleo por Yrigoyen, quien había fundado anteriormente YPF) entra en vigor "el decreto del 8 de enero de 1931, firmado por el ministro de Relaciones Exteriores y Culto de la Nación, Ernesto Bosch, por el que se encomendaba a Rossi y Bosch aquella misión en Europa [capacitar a quienes deberían asesorar al Poder Ejecutivo Nacional en materia de eugenesia y medicina social], que ambos cumplieron a lo largo de trece meses, pasados en su mayor parte junto a Pende en el Instituto Biotipológico de Génova" ${ }^{63}$. Así, pues, en 1932 -año en el que José Félix Uriburu es reemplazado por un reconocido admirador de Mitre, Agustín Pedro Justo, quien aparta a los yrigoyenistas de la Unión Cívica Radical de la vida pública- nacerá en la capital la Asociación argentina de Biotipología, Eugenesia y Medicina Social. Agustín Pedro Justo no sólo había estrechado la relación Iglesia-Estado en Argentina sino que en 1934 consiguió, con el Congreso Eucarístico, un gran éxito en su iniciativa por recuperar el espacio social que ya se daba por perdido:

Se celebraba un acto público, con apoyo y presencia de las autoridades gubernamentales, donde lo religioso constituía por vez primera la razón, si bien no única, de una impresionante manifestación masiva que recorrió las calles de la ciudad. Para el cardenal Eugenio Pacelli, Secretario de Estado del Vaticano y delegado papal en el Congreso, fue el primero de una serie de viajes oficiales con los que

59 "En abril de 1934, el gobierno de Gabriel Terra aprobó el Código del Niño [...] En ese Código se consagró la principal medida eugenista de la legislación uruguaya, pues su artículo 27 indicaba hacer «propaganda persuasiva para obtener la mayor concurrencia de futuros cónyuges a los Consultorios Médicos Prenupciales, a cargo del Ministerio de Salud Pública». Los oficiales del Registro del Estado Civil, por su lado, «aconsejarán a los futuros cónyuges acerca de la ventaja de la consulta prenupcial dejando constancia en el acta de la inscripción de haberlo hecho así»»" Ibidem, p. 47.

60 La relación entre anarquismo y eugenesia, no desarrollada en el análisis de Stepan, ha sido muy recientemente analizada por Nadia Ledesma cuya "hipótesis es que, desde la mirada anarquista, el discurso de la eugénico tuvo una singular apropiación que, contrario a lo establecido en relación con otros propulsores de esa ciencia, en el caso ácrata contribuyó a redefinir los deberes y derechos de las mujeres" de modo que estas pudieran vivir su sexualidad más deshinibidamente, aprovechando los conocimientos que sobre anticoncepción brindaba el saber eugénico. Véase N. Ledesma, "Apuntes sobre la eugenesia y la libertad sexual en el discurso de dos médicos anarquistas. Argentina, 1930-1940", Nomadias 16 (2012), p. 77.

61 Ibidem

62 N. L. Stepan, The hour of eugenics: race, gender, and nation in Latin America, Cornell University Press, 1991, p. 58.

63 G. Vallejo y M. Miranda, "“Civilizar la libido": estrategias ambientales de la eugenesia en la Argentina", Iberoamericana (2001-), 2011, pp. 62-63. 
coronó su brillante carrera diplomática antes de ascender al papado como Pío XII. Junto a él en las ceremonias públicas celebradas en la ciudad, la figura del presidente Agustín P. Justo simbolizaba la reconciliación de las relaciones entre la Iglesia Católica y el Estado argentino ${ }^{64}$.

Sobre este fondo se recorta la figura clave, ya mencionada en la parte I de este artículo, de Zacarías de Vizcarra. Este obispo vasco (hijo de un carlista próximo a "Carlos VII") forma con Ramiro de Maeztu (a quien aquel asesoró espiritualmente durante sus años de embajador del gobierno de Miguel Primo de Rivera en Argentina, entre 1928 y 1930) y Vallejo Nágera un peculiar tridente en defensa de la idea nacional-católica de la Hispanidad. En efecto, "fue Ramiro de Maeztu quien primero aludió -«la palabra (Hispanidad) se debe a un sacerdote español»- a Zacarías de Vizcarra como creador del concepto"65.

Vizcarra participó en la organización del Congreso Eucarístico arriba mencionado en calidad de Prosecretario. A dicho Congreso asistió el Arzobispo de Toledo, quien el 12 de octubre de aquel año de 1934 se encargó del discurso de la celebración de la Fiesta de la Raza. Este sacerdote vasco, afincado en Argentina desde comienzos de la década de los 10, además de participar en cursos de cultura católica (19221925), impartir lecciones sobre "Patriotismo" (1925), pedir a la RAE que se acepte el término "Hispanidad" (1926), colaborar, asesorar y ejercer la censura eclesiástica en la revista Criterio (desde 1928) -donde propone el uso del término "Hispanidad" en lugar de "Raza" y se recogerán los aportes de Vallejo Nágera- y publicar el artículo "La palabra Hispanidad" (1929), había dado a la luz pública en Buenos Aires un año antes (1933) del Congreso Eucarístico la obra La vocación de América:

En la parte I “América y el 12 de Octubre” [...] Vizcarra critica el uso del término "Raza", por cuanto pudiera connotar " raza física", añadiendo que sólo lo podría admitir a condición de que con ello se entendiera "el tipo nuevo de humanidad modelado en nuestro continente con la mezcla de sangre, cultura, religión, lengua y tradiciones de los pueblos ibéricos". Insiste en el aspecto religioso del 12 de octubre [...] y cita las palabras que escribió el Pontífice León XIII el 16 de julio de 1892 [...] En la parte II “América y las misiones" [...], Vizcarra hace relación de "la enorme actividad misionera desplegada en América" [...] Apostilla el Código de Leyes de Indias como "el mejor éxito de la obra evangelizadora" [...] Añade Vizcarra cómo otras naciones colonizadoras, fuera de las ibéricas, "adoptaron un sistema enteramente contrario, impidiendo en toda forma la mezcla de razas, hasta con severísimos castigos legales" $"$.

Es en este momento en el que Vallejo Nágera, "cuya influencia ideológica en el medio local sobrepasa, claramente, sus menciones específicas"67, hace aparición en los medios académicos argentinos. En 1936 las tensiones crecen, el 1 de mayo

64 J.-M. Ghio, La iglesia católica en la política argentina, Prometeo Libros Editorial, 2007, p. 74.

65 H. Tateishi, "Zacarías de Vizcarra y La vocación de América: Apuntes sobre la Hispanidad y el nacional-catolicismo", Mediterranean world= 地中海論集 17 (2004), p. 45.

66 Ibidem, pp. 48-49.

67 M. Miranda, "Noviazgo y eugenesia en ámbitos latinos: «casar selectos para parir selectos»", Cadernos de Pesquisa Interdisciplinar em Ciências Humanas 15:107 (2014), p. 58. 
supondrá un éxito de convocatoria y de organización sin precedentes (asimilando el himno nacional a la causa de los trabajadores) y se hace por fin patente que la corrupción y el fraude electoral comienzan a ser insoportables para la sociedad. Así pues, en 1937, un año antes de la toma del poder por el radical antipersonalista Roberto Ortiz, el facultativo José Belbey ${ }^{68}$ publica en los Anales de la Facultad de Ciencias médicas de la Plata su artículo "La esterilización humana por el estado", cuyas primeras líneas dicen:

El doctor A. Vallejo Nájera (sic), en un libro de reciente aparición en Madrid, dice que temía mucho que las disueltas Cortes "arrastradas por el entusiasmo de dictar leyes avanzadas, hubieran aprobado a la ligera un proyecto de esterilización". Parecidamente inicio este pequeño trabajo temiendo a mi vez, pero ante circunstancias distintas, que algún día de estos surja entre nosotros un proyecto de esterilización parecido al promulgado por el Führer Hitler. [...] Colaboro en mi medida a evitarlo. No con el criterio del distinguido colega hispano ya mencionado, que huele más que a biólogo, a sacristía ${ }^{69}$, sino con un punto de vista absolutamente ajeno a todo dogma, ya sea éste religioso o político ${ }^{70}$.

Como alternativas a la esterilización, Belbey propone el internamiento obligatorio para los alienados hasta que completen el tratamiento, la vigilancia de los ex-alienados, la permisión del aborto independientemente de que el alienado sea el padre o o la madre, la aprobación de leyes de "estado peligroso" recuperando un proyecto de la presidencia de Alvear, impulsar y ampliar en su radio la acción de la Higiene mental, permitir el divorcio de los alienados incurables, declarar como delito el contagio venéreo, mejorar las condiciones económicas de la población trabajadora y, finalmente, evitar que una futura cerrazón sea posible en el futuro, es decir, evitar que lo hecho sea revertido ${ }^{71}$.

Habrá que esperar exactamente una década para que aparezca de nuevo Vallejo Nágera -así como otros autores españoles como Emilio Mira y August Pi Súñer- en una publicación médica especializada argentina al respecto de la cuestión eugénica: "La eugenesia positiva en lo hereditario y lo ambiental", del doctor Benjamin Spota, aparecido en agosto de 1947, año que "fue el de mayor cercanía en las relaciones Iglesia-Estado. Este "idilio" cuya razón principal fue la legalización de la enseñanza católica obtenida en marzo [...] La empresa de reunificación de la sociedad argentina, que el tiempo se encargaría de demostrar como de imposible realización, se edificó desde el Estado bajo

${ }_{68}$ J. Belbey sería presidente de la Sociedad de Medicina Legal y Toxicología y de la Asociación Médica Argentina (1958-1960). El premio que otorga esta institución lleva actualmente su nombre.

69 Ciertamente, la vinculación de Vallejo Nágera con el catolicismo era pública y manifiesta, como se expuso en la parte I de este artículo, cuando se expuso la semblanza del concepto de "raza" como el acarreo de pensamiento e idioma: "Desde [la revista argentina nacionalista y católica dirigida por Monseñor Gustavo Franceschi desde 1932 a 1957] Criterio se siguió la intervención de Vallejo Nágera en el Segundo Congreso Internacional de Médicos Católicos, celebrado en Viena entre el 28 de mayo y el 3 de junio de 1936. En esa ocasión, el español coincidió con Gemelli quien era por entonces rector de la Universidad de Milán y concurrió al Congreso en representación del Papa Pío XI. Las posturas que Vallejo Nágera y Gemelli defendían confluyeron en un programa común." En G. Vallejo y M. Miranda, ’Iglesia católica y eugenesia latina: un constructo teórico para el control social (Argentina, 1924-1958)", Asclepio, 66:2 (2014), p. 5.

70 J. Belbey, "La esterilización humana por el Estado", Anales de la Facultad de Ciencias Médicas de La Plata 1 (1937), pp. 282-283.

$71 \quad$ Ibidem, pp. 291-292. 
las líneas en que el nacionalismo católico venía trabajando por más de una década: revalorización de la hispanidad, nacionalismo católico y corporativismo social" (cursivas nuestras). En efecto, en el artículo, el doctor Spota -Vicepresidente $1^{\circ}$ de la Sociedad Argentina de Eugenesia- expone la diferencia entre eugenesia negativa y positiva y habla abiertamente de factores heterotóxicos (de nuevo, la blastoftoria en el horizonte) poniendo énfasis en que son más perjudiciales para la mujer, la cual es, según Spota, el principal elemento del "binomio eugénico". Aparecen en su descripción del estilo de vida heterotóxico para la herencia elementos muy semejantes a los que con ahínco criticara Vallejo Nágera: la "desvitaminosis adquirida con fines de falsa aspiración estética, propendiendo a la creación de un tipo somático femenino por entero artificial y premórbido, el «snobismo», el desmedido afán de lujo, la cursilería cinematográfica y los espejismos que trae aparejados, propende a la relajación del vínculo sagrado familiar"72. En cualquier caso Vallejo Nágera le sirve como argumento de autoridad contra la teoría de la degeneración, a la que se califica de anti-científica y subraya, además, cómo tanto Vallejo Nágera como Mira distinguen entre factores patogénicos y patoplásticos de la personalidad. Finalmente, citando el Tratado de Psiquiatría de Vallejo, se hace hincapié en que los factores patogénicos vinculados a la psicosis son recesivos por lo que las psicosis endógenas no pueden erradicarse por medios eugenéticos "negativos" -recuérdese, en la parte I del presente artículo, las tesis de Vallejo en Higiene de la raza: la asexualización de los psicópatas.

Tras otros diez años, Vallejo Nágera vuelve a aparecer en un documento especializado del ámbito médico y relacionado con la eugenesia, esta vez como una referencia bibliográfica (a la que acompaña también la del artículo de Spota aquí citado). Se trata de "La degradación cosista del hombre. Valoración del humanismo eugenésico integral" (edición propia, Buenos Aires, 1957), de Carlos Bernaldo de Quirós, autor prolífico, miembro de un Tribunal superior de Justicia y espoleador del Derecho Eugénico mediante cursos en instituciones, entre ellas la Escuela Politécnica de Biotipología.

Dos años antes de la publicación del texto de Quirós, Perón ha sido depuesto, en buena medida, a causa de todo lo que conllevaron los bombardeos de la Plaza de Mayo, la quema de la bandera y todo ello siempre en relación con el conflicto con una Iglesia Católica ya alarmada por el nuevo espíritu evangélico paralelo que el peronismo "de movimiento" estaba albergando -a la par que el peronismo "de gobierno", que toleraba este "evangelismo" (e, incluso, lo fomentaba mediante la figura de Eva Duarte) mantenía, no obstante, las relaciones con la Santa Sede. En 1954 estas relaciones se rompen dramáticamente:

El Congreso sancionó rápidamente la ley que suprimió las diferencias entre hijos legítimos y extramatrimoniales, el divorcio vincular, una nueva ley de profilaxis, el levantamiento de exenciones impositivas a la Iglesia, una nueva reglamentación sobre reuniones en espacio públicos que requería expresa autorización del Ministerio del Interior, y el Poder Ejecutivo anunció el envío al Congreso de un nuevo proyecto de reforma constitucional que separara la Iglesia del Estado. Esta contraofensiva oficialista culminó en abril de 1955, cuando suprimió la enseñanza religiosa de las escuelas públicas, que se impartía desde 1943. A todo esto, exhi-

72 B. Spota, "La eugenesia positiva en lo hereditario y ambiental", La Semana Médica, Buenos Aires, Año LIV, Número 2797, p. 299. Recoge la conferencia pronunciada el 29 de mayo del mismo año en el $2^{\circ}$ acto público de la Sociedad Argentina de Eugenesia. 
biendo una vez más su vocación igualitarista y transgresora -desafiando el poder y el prestigio de la Iglesia católica en la sociedad-, Perón recibió en esos mismos días una condecoración de la Iglesia ortodoxa que notoriamente exaltada por la prensa. [Cita: Leyes 14.367 sobre "Hijos nacidos fuera del matrimonio", publicada en el Boletín Oficial el 3 de noviembre de 1954 (proyecto presentado por el diputado Antonio J. Benítez) y la 14.394, sobre "Divorcio, régimen penal de menores, edad para contraer matrimonio, ausencia con presunción de fallecimiento, bien de familia", publicada en el Boletín Oficial el 30 de diciembre de 1954 (sobre proyecto del Poder Ejecutivo) $]^{73}$.

Siguiendo en lo consecutivo a Marisa Miranda, ha de de reconocerse que, en este contexto, Quirós sería ya un autor de la "tardo-eugenesia", es decir, de la eugenesia a la medida de la Iglesia y donde la voz de Vallejo Nágera, recogida por Criterio, fue escuchada:

En 1945 el abogado Carlos Bernaldo de Quirós funda la Sociedad Argentina de Eugenesia, desvinculándose así de la Asociación Argentina de Biotipología, Eugenesia y Medicina Social, convertida en Instituto Nacional de Biotipología y Materias Afines por el gobierno de Juan Domingo Perón. De esta manera, Bernaldo de Quirós quedará constituido en una figura emblemática en cuanto a la perduración del paradigma eugénico luego de la Segunda Guerra Mundial. En efecto, en torno suyo no sólo se mantuvo sino que se acrecentó la vertiente eugénica de sesgo ambiental (mal llamada neolamarckiana) sobre la cual se asentara el eugenismo local de la segunda mitad del siglo $\mathrm{XX}^{74}$.

Y, en efecto que puede decirse que no era neolamarckiana, mas no sólo por razones epistemológicas (por no atacarse la blastoftoria sino acometerse la selección de novios para perfectos matrimonios) sino porque en el caso de Argentina se trataba ya, más bien, de una vertiente nacional-católica e hispana que, si bien no pudo arraigar como "nacional-catolicismo" al estilo de la antigua metrópolis debido a la heterogeneidad que alimentaba al caudillismo peronista (tan distinta de la homogeneidad prontamente impuesta por el Caudillo español), sí -y tras la desacreditación post-Holocausto de toda eugenesia negativa- quedó como un nuevo punto de partida para las instituciones médicas y religiosas argentinas:

Desde 1945 y hasta entrada la década de 1970 fue la Sociedad Argentina de Eugenesia, de la mano del prolífico jurista Carlos Bernaldo de Quirós, la entidad encargada de difundir las pretendidas "bases científicas" que avalarían la exclusión. Exclusión cuyo mecanismo ya no era la deportación material, la transferencia fuera del espacio social, sino el aislamiento dentro del espacio moral, psicológico, público; por lo que, desde una perspectiva foucaultiana, al igual que en el panóptico, en la "nueva Eugenesia" ya no había indagación sino vigilancia, examen ${ }^{75}$.

73 M. E. Spinelli, Los vencedores vencidos: El antiperonismo y la "revolución libertadora", Editorial Biblos, 2005 , p. 32.

74 M. Miranda, "La tardo-eugenesia en Argentina: un enfoque desde la longue durée”, Arbor, 189:764 (2013), pp. 3-4.

75 M. Miranda, "La antorcha de Cupido: eugenesia, biotipología y eugamia en Argentina, 1930-1970”, Asclepio 
En efecto, y de acuerdo con las tesis críticas (Miranda, Vallejo, Stern...) con la visión maniquea de la cuestión eugénica, creemos que puede diferenciarse aquí, por una parte, la representación propia (en clave siempre positiva) que de sí hizo y transmitió por vía de las publicaciones académicas (influyendo en sus historiadores posteriores) el discurso eugénico "positivo" -latinoamericano en general e hispanoargentino en particular- de, por otra parte, el efectivo ejercicio que se proponía llevar a cabo dicho discurso sobre las sociedades de implantación en la cotidianidad, de modo que si bien de la eugenesia nacional-católica no puede decirse que negara físicamente el intercambio sexual de plasma germinal a los no selectos, sí puede asegurarse que pretendía privar preventivamente (recuérdese lo expuesto sobre la ley sueca por Vallejo en la parte I de este artículo) del derecho al matrimonio a los enfermos psiquiátricos severos, con las consecuencias -usando la expresión de Mirandade "aislamiento social" que para esta forzosa soltería (recuérdese lo expuesto sobre la semblanza de la figura del mal patriota, mal ciudadano y enfermo "solterón", en la parte I) podría conllevar en las sociedades que estaban por venir a ambos lados del Atlántico -española y argentina- a partir de mediados de la década de los cuarenta. $\mathrm{Y}$ es que, recuérdese, para la concepción nacional-católica "la verdadera eugénica consiste en apartar del matrimonio a los que no pueden cumplir sus fines". 